\title{
Design and Fabrication of A Gas Cooker using Recycled and Readily Available Materials
}

\author{
Charles Murithi Maina \\ Department of Industrial and Energy Engineering, \\ Egerton University, Kenya
}

\begin{abstract}
In this work, gas cooker was designed and fabricated from recycled and readily available materials. The purpose of the project was to substantially reduce the cost of the cooker which is currently imported and being sold at high prices making it unavoidable for many households. Using recyclable and readily available materials, the cost of the designed and fabricated cooker was reduced thus making it possible for a large number of people to get the gas cooker with relative ease and popularize the use of gas cooking as a clean source of energy in place of the more dominant kerosene, firewood and charcoal used in urban and rural households due to some environmental and health challenges associated with the latter. Through simple project design, a reliable gas cooker was fabricated whose test results were comparable with commercially imported gas cookers/stoves.
\end{abstract}

Keywords: Fabrication, Design, Recycled Materials, Gas Cooker, Cooking Fuel

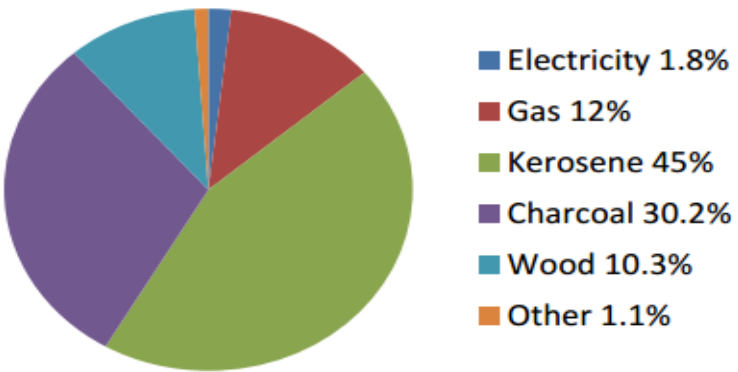

Fuels Used for Cooking Urban Areas (UNDP/WHO 2009)

\section{INTRODUCTION}

A vast majority of households in developing countries such as Kenya heavily depend on biomass energy resources such as charcoal, agricultural wastes and firewood as the main sources of cooking fuel. High dependence on biomass energy sources has been necessitated by increased poverty levels that are responsible for the significant shift to nontraded traditional biomass fuels from $73 \%$ in 1980 to $83 \%$ by 2015 [1]. Although other sources of cooking fuels such as Liquefied petroleum gas (LPG) and kerosene are used in some households, charcoal and firewood are the most commonly used sources of cooking fuel [2]. Energy survey indicates that firewood is the most preferred source of cooking fuel for rural households while charcoal is common amongst urban households. For instance, $88.2 \%$ of rural households depend on firewood for cooking and heating against $10.3 \%$ of the urban households while $30 \%$ of urban households use charcoal as part of their energy mix against $7.7 \%$ of rural households using charcoal (see Fig. 1.1).

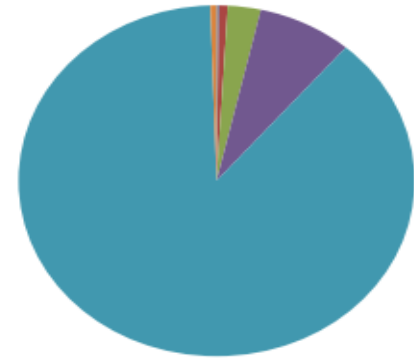

Electricity $0.2 \%$

- Gas $0.7 \%$

Kerosene $\mathbf{2 . 7 \%}$

charcoal $7.7 \%$

Wood $88.2 \%$

Other $0.5 \%$

\section{Fuels used for Cooking Rural Areas} (UNDP/WHO 2009)

Figure 1.1: Sources of cooking fuel for urban and rural households in Kenya

Fig. 1.1 shows that wood, charcoal and kerosene are widely used sources of cooking fuel for both rural and urban households compared to gas and electricity combined. However, wood, charcoal and kerosene are attributed to health and environmental challenges such as issues of deforestation and emission of greenhouse gases (GHG) during carbonization of charcoal and wood fuel. For instance, about 7.2 and $9.0 \mathrm{~kg} \mathrm{CO}_{2}$ equivalent is released to the environment for every $1 \mathrm{~kg}$ of charcoal produced [3, 4]. The emitted GHG is responsible for different conditions such as acute infections of the lower respiratory track amongst young children and chronic obstructive pulmonary disease in adult women $[5,6,7]$ as the two groups spend more time in the kitchen [8]. Using firewood for cooking in open fires such as three stones stoves produces 100 times more fine particulate matter responsible for more than half the deaths of children below age of five. According to World Health Organization (WHO) risk assessment based on results of different published research findings, solid fuels are responsible for 800,000 to 2.4 million premature deaths each year [9]. To deal with the health and environmental problems associated with the use of firewood, charcoal and kerosene, both rural and urban households should adopt the use of LP gas as cooking fuel since it is clean source of fuel hence does not cause health-related and environmentalrelated problems $[10,11]$. Gas is not only environment 
friendly but is also affordable when used in form of biogas. LPG has also been proven to be more economical than conventional sources of fuel. Although cooking using LP gas is economical than conventional sources of fuel, the former is expensive and inaccessible for most households in third World countries. This is because most gas cookers are imported thus households require substantial capital to buy LP gas cooker and cylinder thus limiting its use as cooking fuel. Therefore, there should be initiatives aimed at reducing the overall cost of purchasing LPG hardware such as gas cooker, thus, this research work. The current research work designed, fabricated and tested a gas cooker (or stove) using recycled and readily available materials with the objective of making gas cheaper and the most stable source of cooking fuel for rural and urban households thus eliminating health and environmental problems associated with conventional sources of cooking fuel.

\section{METHODS AND MATERIALS}

\subsection{Design Analysis}

The design analysis of a gas cooker using recycled and readily available material involved gathering information on

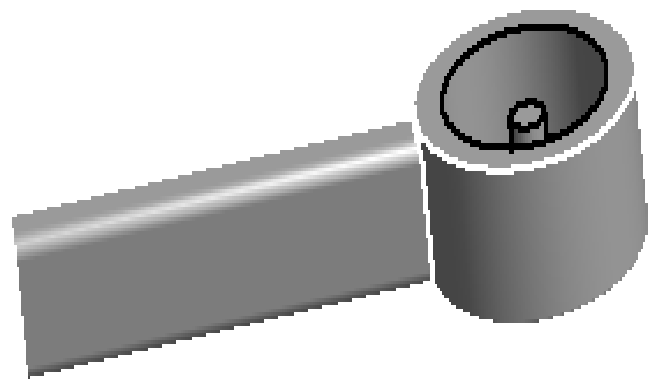

Figure 2.1(a): Bottom part parts used in making a gas cooker, analyzing the parts and choosing the ones that can be made from readily available materials and ones that are standard parts to be purchased and studying the materials the parts are made from and suggesting alternative materials where necessary. The design was done to ensure that the cooker withstands normal usage as well as using simple tools thus making the cooker cheap and eliminating the need for precision machining.

\subsection{Analysis of parts of the gas cooker}

\subsubsection{The burner}

The burner was made of two parts which were purchased from local supplier. The bottom part which was cast from recycled aluminium serves as a fixing point for mixing tube. This part was designed with a cylindrical tube to facilitate reduction of pressure. The choice of recycled aluminium was based on high resistance to corrosion, low expansivity rate, better wear resistance, better welding characteristics, excellent fluidity characteristics, less prone to shrinkage, light in weight properties and excellent surface finish hence no additional aesthetic additive after casting [12]. The top part of the burner was machined from recycled brass.

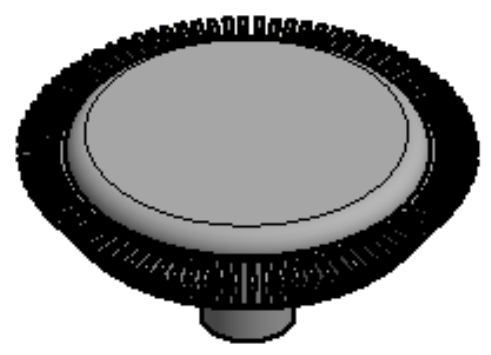

Figure 2.1(b): Top part

\subsubsection{Construction of the frame}

The frame was fabricated from mild steel which was cut into correct dimensions and sizes and joined together through welding process (see Fig. 2.2).
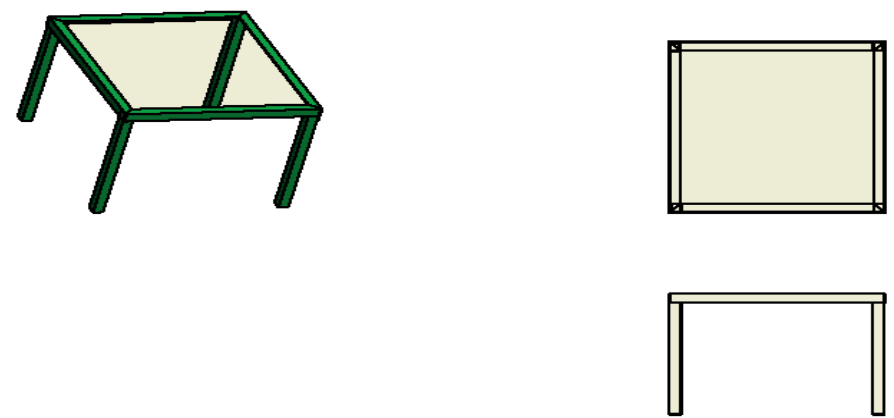

Figure 2.2: Welded frame joints 
(a) Analysis of stresses in welded joints

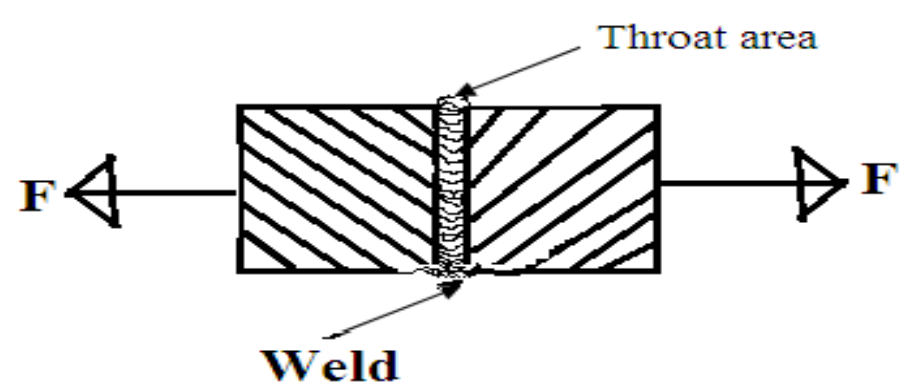

$\sigma=\frac{F_{n}}{A}=\frac{(\text { Load })}{\text { Area of weld }}$

(1)

Joint efficiency $=\frac{\text { Tensile strength of joint }}{\text { Tensile strength of parent material }} \times 100 \%$

\subsubsection{Pan supports}

The purpose of pan supports is to facilitate the positioning of pans on top of the burner. In this project, the supports were fabricated using mild steel gauge plate $25.4 \mathrm{~mm}$, chamfered at $45^{0}$ to direct the flame towards the central point of the pan being heated. The support pieces were welded to

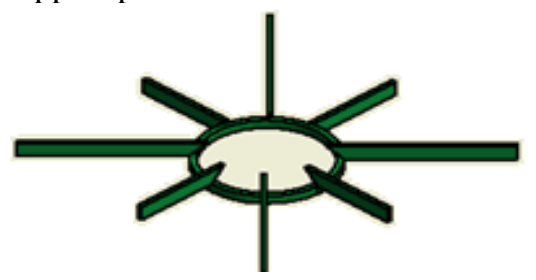

Figure 2.3: Pan Support

\subsubsection{Copper tube}

Copper tubes facilitate the flow of LP gas to the burner. Copper tubes were selected from the range of tubes available in the market. The choice was based on copper properties such as corrosion resistant and good machinability. The copper tube was designed in two parts joined together by a control tap to regulate the flow of gas hence the size of flame.

\subsubsection{Mixing tube/pipe}

A mixing pipe $180 \mathrm{~mm}$ in length with an outside diameter of $32 \mathrm{~mm}$ and an inside diameter of $24 \mathrm{~mm}$ with a slot of 40 $\mathrm{mm}$ on one side that is fixed with an adjustable socket screw

$\sigma_{t}=\frac{P\left(r_{1}\right)^{2}}{\left(r_{0}\right)^{2}+\left(r_{1}\right)^{2}}\left[1+\frac{\left(r_{0}\right)^{2}}{(x)^{2}}\right]$

And radial stress at any radius $\mathrm{x}$,

$\sigma_{r}=\frac{P\left(r_{1}\right)^{2}}{\left(r_{0}\right)^{2}-\left(r_{1}\right)^{2}}\left[1-\frac{\left(r_{0}\right)^{2}}{(x)^{2}}\right]$

Where $\mathrm{P}=$ internal fluid pressure in the pipe.

$$
\begin{aligned}
& r_{1}=\text { Inner radius of pipe. } \\
& r_{0}=\text { Outer radius of pipe } \\
& \sigma_{t}=\text { Tangential stress. } \\
& \sigma_{r}=\text { Radial stress. }
\end{aligned}
$$

The tangential stress is maximum at the inner surface (when $\mathrm{x}=r_{1}$ ) of the pipe and minimum at the outer surface $\left(\right.$ when $\mathrm{x}=r_{0}$ ) of the pipe. Substituting the values of $\mathrm{x}=r_{1}$ and $\mathrm{x}=r_{0}$ in the equation (3), maximum tangential stress at the inner surface of the pipe is given by Eq. (5).

$\sigma_{t(m x m)}=\frac{P\left[\left(r_{0}\right)^{2}+\left(r_{1}\right)^{2}\right]}{\left(r_{0}\right)^{2}-\left(r_{1}\right)^{2}}$

And the minimum tangential stress at the outer surface of the pipe is given by Eq. (6).

$$
\sigma_{r(m x m)}=\frac{2 P\left(r_{1}\right)^{2}}{\left(r_{0}\right)^{2}+\left(r_{1}\right)^{2}}
$$


From the equation it can be concluded that the radial stress is maximum at the inner surface of the pipe and zero at the outer surface of the pipe. Substituting the values of $\mathrm{x}=r_{1}$ and $\mathrm{x}=r_{0}$ into equation (4), the maximum radial stress at the inner surface is given as:

$\sigma_{t(m x m)}=-\mathrm{P}($ compressive $)$

And the minimum radial stress at the outer surface of the pipe is:

$$
\begin{aligned}
\sigma_{\mathrm{r}(\mathrm{mxm})} & =0 \\
\sigma_{r(m x m)} & =\frac{2 \times 30 \times 10^{5}\left[(0.016)^{2}\right]}{(.012)^{2}+(.016)^{2}} \\
& =3.84 \mathrm{Mpa}
\end{aligned}
$$

\subsubsection{Design of the pipe}

The design of the pipe involved the determination of the inside diameter of the pipe and its wall thickness. The inside diameter $r$ of the pipe depends upon the quantity of fluid to be delivered.

$\mathrm{Q}=\mathrm{AV}=\frac{\pi}{4} \times \mathrm{D}^{2} \times \mathrm{V}$

Where $\mathrm{D}=$ Inside diameter of the pipe.

$\mathrm{V}=$ Velocity of flow per minute.

$\mathrm{Q}=$ Quantity of fluid per minute.

$\mathrm{A}=$ Area of the pipe.

Therefore $\mathrm{D}$ can be expressed as: $\mathrm{D}=\sqrt{\frac{4}{\pi} \times \frac{P}{V}}=1.13 \sqrt{\frac{Q}{V}}$

Wall thickness is critical in withstanding the pressure of fluid. Pressure $(\mathrm{P})$ may be obtained by using thin cylindrical or thick cylindrical formula

The cylindrical formula may be used when:

a) Stress across section of the pipe is uniform.

b) Internal diameter of the pipe is more than 20 times wall thickness i.e. $\frac{d}{t}>20$

c) The allowable stress $\left(\sigma_{t}\right)$ is more than 6 times the pressure inside the pipe $(\mathrm{P})$ i.e. $\frac{\sigma_{t}}{P}>6[13,14]$.

\subsubsection{Selection of nozzle (jet)}

The purpose of nozzles in LPG installations is to impact enough momentum from the mixing tube to enable the gas to reach the burner without any leakage. To achieve this, this project used a convergent type of nozzle (see Fig. 2.4).

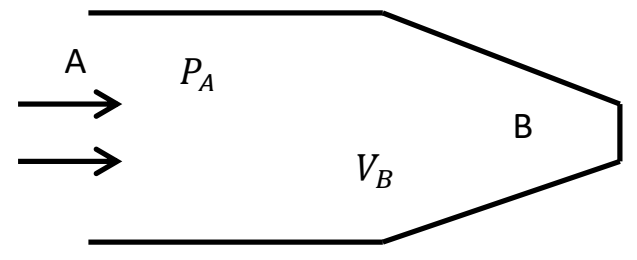

Figure 2.4: Convergent LP gas Nozzle

The convergent nozzle was designed to facilitate the entry of gas at point $\mathrm{A}$ at low pressure $\mathrm{P}_{\mathrm{A}}$ and leaves the nozzle at point $\mathrm{B}$ at very high velocity $V_{B}$. The high velocity $V_{B}$ implies lower pressure at point $B$ thus forcing air up the pipe to mix with LP gas. The momentum of the jet carries the mixture through the mixing tube which acts as a diffuser whereby the velocity decreases and the pressure increases to the outlet valve at the burner head. The aeration slot can be varied with an adjustable socket screwed onto the burner tube.

$$
C_{c}=\sqrt{\left(C_{\gamma} P_{c} V_{c}\right)}
$$

Where $C_{c}=$ exit velocity

$P_{c}=$ absolute pressure at gas inlet $=103.04 \mathrm{KN} / \mathrm{M}^{2}$

$C_{\gamma}=$ critical velocity at throat $=1.11$

$V_{c}=$ specific volume of $\mathrm{LPG}$ gas $=0.385 \mathrm{~m}^{3} / \mathrm{kg}$

$\mathrm{C}_{\mathrm{c}}=\left(1.11 \times 103.04 \times 10^{3} \times 0.385\right)^{1 / 2}$

Flame Velocity $=210 \mathrm{~m} / \mathrm{s}$

\subsubsection{Body}

The height of the burner head to the pan supports affects the relative positions of the burner and the bottom of the pan hence is critical in the design of gas cooker/stove. The body comprised of top rectangular frame welded into place to ensure $90^{\circ}$ corners. 
The stands were then welded at $90^{\circ}$ vertically to the frame. The top frame was positioned for the burner. At the end of the frame, a piece of tubing was used to provide an anchoring facility for the support strip.

\subsubsection{Final assembly}

The final assembly of the gas cooker is presented below. The performance of the designed and fabricated gas cooker was tested using 1 liter of water, a cooking vessel, a thermometer and a stopwatch. The aim was to measure the time taken to boil 1 litre of water.

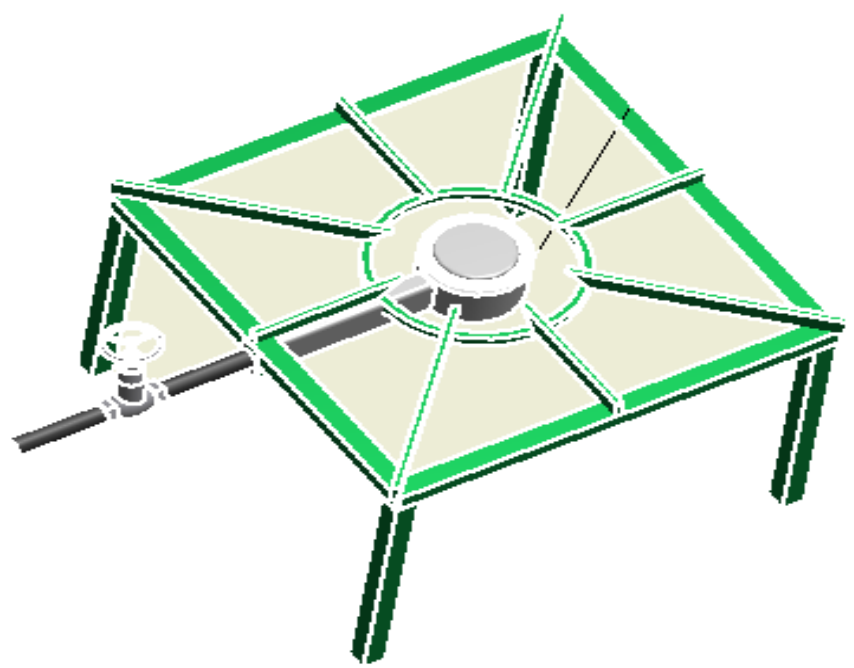

Figure 2.5: Gas cooker final assembly

\section{RESULTS AND DISCUSSIONS}

Recyclable and readily available materials such as steel, bronze, copper and aluminium were used in fabricating various components of LP gas cooker/stove such as the frame. This resulted in substantial reduction in the overall cost of the gas cooker compared to imported gas cookers especially through mass production of the various components of the cooker. When the cooker was switched on followed by adjustment of the knob, the cooker lit up with a non-luminous flame. The produced flame was efficient and sufficient for domestic applications such as cooking. The sufficient adjustment of the cooker facilitated the production of different flame sizes depending on desired applications. The test results of the cooker indicated that the efficiency and working conditions of the cookers were within the range of commercially imported gas cookers/stoves available in the market.

\section{CONCLUSION}

In this project work, a gas cooker was designed and fabricated using recycled and readily available materials such as aluminium and steel. The design of the fabricated gas cooker involved analysis of the flow of gas from the gas cylinder to the burner. To achieve right gas to air ratio mixture in the burner, crucial design features such as mixing tube with the air slot, mixing chamber and nozzle were taken into consideration with the objective of achieving and maintaining the right cooking flame. Using safety measures and precautions, a simple design of the cooker with few parts was done aimed at reducing the production cost of the cooker, thus, making cooking using gas readily available, cheaper and most stable source of cooking fuel for both rural and urban households. This will help in addressing the environmental and health challenges such as deforestation, acute infections of the lower respiratory track and chronic obstructive pulmonary disease associated with conventional sources of fuel such as firewood and charcoal. The test results showed that the fabricated gas cooker achieved the average time required to boil one-litre of water.

\section{ACKNOWLEDGMENT}

The author is grateful to the Department of Industrial and energy engineering, Egerton University, Kenya, for providing laboratory support for this study.

\section{REFERENCES}

[1] Bonjour, S. et al. (2013): Solid Fuel Use for Household Cooking: Country and Regional Estimates for 1980-2010, Environmental Health Perspectives, p 784-790, Volume 121, number 7, July 2013 http://ehp.niehs.nih.gov/wpcontent/uploads/121/7/ehp.1205987.pdf.

[2] Ministry of Energy (2002), Study on Kenya's Energy Demand, Supply and Policy Strategy for Households, Small scale Industries and Service Establishments. Kamfor Consultants, Nairobi, Kenya

[3] Smith, K.R. 1993. Fuel combustion, air pollution exposure, and health: the situation in developing countries. Annual Review of Energy and Environment, 18: 529-566.

[4] Jetter J., Zhao Y, Smith KR, Khan B, Yelverton T, Decarlo P, Hays MD, (2012), Pollutant Emissions and Energy Efficiency under Controlled Conditions for Household Biomass Cookstoves and Implications for Metrics Useful in Setting International Test Standards. Environ Sci Technol. 2012 Oct 2;46(19):10827-34. doi 10.1021 / es301693f. Epub 2012 Sep 17. For non-commercial research and education use, a copy of the article can be accessed at: http://ehs.sph.berkeley.edu/krsmith/?p=1387

[5] Bailis R., et al. (2003): Impacts of greenhouse gas and particulate emission from woodfuel production and end-use in Sub-Saharan Africa. 
[6] Smith, K.R., Rogers, J. \& Cowlin, S.C. 2005. Household fuels and ill-health in developing countries: what improvements can be brought by LP gas (LPG)?Paris, France, World LP Gas Association \& Intermediate Technology Development Group.

[7] Bruce NG, Perez-Padilla R, Albalak R. Indoor air pollution in developing countries: a major environmental and public health challenge. Bulletin of the World Health Organization 2000, 78:1078-1092.

[8] Lim, S.S. and Vos, T. 2012. A Comparative risk assessment of burden of disease and injury attributable to 67 risk factors and risk factor clusters in 21 regions, 1990-2010: a systematic analysis for the global burden of disease study 2010. Lancet 380: 2224-60.

[9] Smith, K.R., Mehta, S. \& Maeusezahl-Feuz, M. 2004. Indoor smoke from household solid fuels. In M. Ezzati, A. Lopez, A. Rodgers, S. Vander Hoorn \& C. Murray, eds. Comparative quantification of health risks: global and regional burden of disease due to selected major risk factors, pp. 1435-1493. Geneva, Switzerland, WHO.
[10] Roth, C. (2013): Setting the scene for ,Emerging Opportunities in Cooking Fuels and Usage' at the Bonn International Cooking Energy Forum, June 2013: https://energypedia.info/wiki/File:Emerging_opportunities_in_co oking_fuels_as_well_as_changing_cooking_habits__Christa_Roth_Bonn_2013.pdf

[11] Smith, K. (2011): Cooking with Gas, Energy for Sustainable Development 15, p 115- 116. Article on usage of fan-assisted gasifier stoves in India. For non-commercial research and education use, a copy of the article can be accessed at: http://ehs.sph.berkeley.edu/krsmith/?p=960.

[12] Myer K. (2002), Handbook of Material Selection. John Wiley \& Sons, Inc. New York.

[13] Hamrock S. J. (2005).Fundamentals of Machine Elements.2nd Edition. Mc Graw Hill, New York

[14] Massey B.S, and John W.S (2005), Mechanics of fluids 8th Edition; Chapman and Hall Publishers London. 